\title{
Interspecific interaction: The analysis of complex structures in carnivorous zooplankton populations
}

\author{
W. GREVE \\ Biologische Anstalt Helgoland (Meeresstation); \\ Helgoland, Federal Republic of Germany
}

\begin{abstract}
Linear unidirectional dependence of one population upon another is rather atypical among zooplankton species, as carnivory is not only characteristic of high trophic levels but also part of omnivory in many species of copepods. The feeding on its predatorjuveniles may be important for the survival of a copepod population, more in regard to the impact on the predator than to the nutritional benefit obtained. Such complex interrelationships are important for predictive ecosystem models. Ctenophore-copepod interrelationships have been analysed in experiments, and the results produced have been used for constructing simulation models. Details of experimentation and of modelling are described and discussed.
\end{abstract}

\section{INTRODUCTION}

The analysis of population interactions in ecosystem analysis is often confronted with food-web structures which cannot be modelled in linear food chains. In the latter it has been proven that transfer efficiency and population control by grazing or predation can be expressed in Lotka Volterra type equations (Landry, 1970; Steele, 1974, 1976). However, Landry (1977), Matthews (1977) and others have

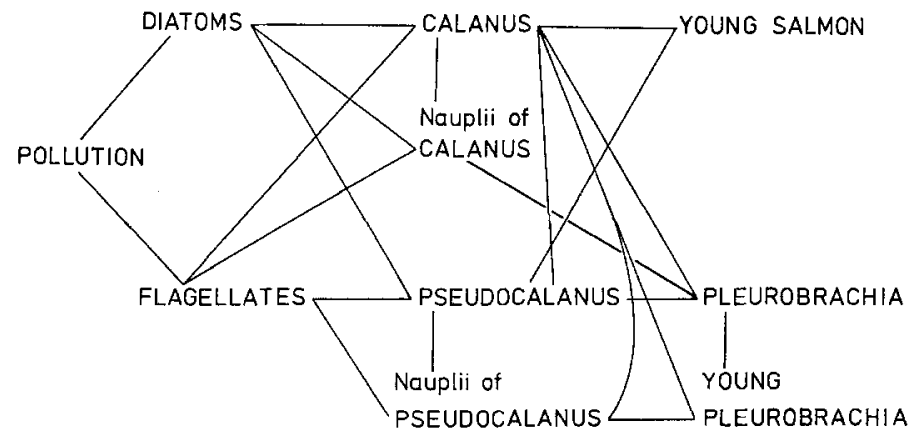

Fig 1: Flow chart of interspecific interactions in "Plitch" (Planktonic switch, a simulation model) showing complex interactive patterns between carnivorous zooplankton species. Changes in the diatom: flagellate ratio cause disturbances at high trophic levels 
shown that, in carnivorous zooplankton, population control may depend on more complex interspecific interaction.

A simulation model of nonlinear food web structures has been constructed describing the switching in a planktonic ecosystem from fish to ctenophores (Biologische Anstalt Helgoland, 1976) (Fig. 1). One decisive part of this food web is the interspecific interaction of Calanus and Pleurobracbia, which is characterised by the predation of the commonly known prey upon the young stages of its predator. This interaction does not seem to be rare in the interspecific dynamics of carnivorous zooplankton (Greve, 1969; Lillelund \& Lasker, 1971; Theilacker \& Lasker, 1974). The mathematical simulation of such complex interactions can be obtained by resolving the overall relationship into simpler experimental components (Holling, 1972). The present paper comprises an attempt to design both the experiments and the model in the form of such an interactive structure.

\section{MATERIALS AND METHODS}

Greve (1969) constructed a graphic model (Fig. 2) which permits the comparison of different interspecific interactions and some predictions of population dynamics in terms of size and composition. The changes in interaction with quality (age, size, sex, health) and quantity which, in the case of some copepods and Pleurobrachia pileus, are inverse trophic relationships with age, can hardly be expressed in the form of a predator-prey system. Therefore, the terms "agent" and "reagent" were introduced, representing the two coordinates in an interaction matrix (Fig. 3). In some cases, the agent may be seen as the prey which acts when nourishing the predator. Again, simultaneous positive and negative effects of one agent upon one reagent could not be utilized for calculations; therefore, three-dimensional diagrams (Fig. 2) were used to replace the symbols in the interaction matrix.

However, in trying to utilize this graphic model for the formulation of equations as the basic rules of a simulation model* (Walters et al., 1974), two major modifications had to be made. The qualitative aspect had to be stressed in the agent as well as in the reagent, while quantitative relationships could be part of the parameters which are calculated within the equations of the model. The second step was the definition of units clearer than "probability of survival" (Fig. 2).

It was chosen to determine positive effects of an interaction as agent carbon gains per reagent carbon, while negative effects of a defined agent upon a defined reagent are determined as losses of individuals. In this way, the Agent-ReagentEffect diagram was developed (Fig. 4) which could be used for calculations as a

* A simulation model of this type consists of the following components (Walters et al., 1974): system state variables - the entities which the model tries to predict and which are indices of the state of the biological system; parameters - constants, such as growth rates which are specific to processes or system variables; equations - stating the basic rules for the calculation of the system state variables - parameter-relationships in each timestep; driving variables representing the world outside the model, which have impact on the system-state variables but not vice versa. 
values matrix, as well as a graphic display of experimental results. The defined interspecific interaction permits the calculation of possible interpopulative interactions though neglecting the antagonistic or synergic effects within the population interactions.

Since Lebour (1922, 1923) first experimentally investigated series of plankton organisms and their trophic interactions the investigations have developed into de-

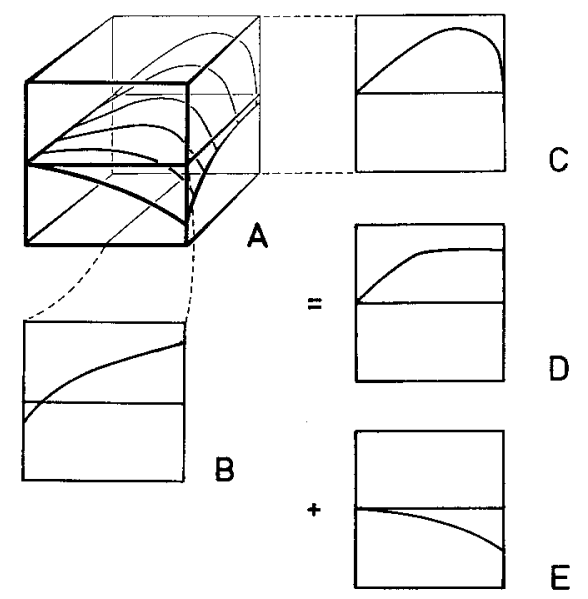

Fig. 2: Hypothetical model of Pleurobracbia-adult Calanus interaction. A basic three dimensional model as to replace the symbols in an interaction matrix (Fig. 3); (x-axis-abundance of adult copepods; z-axis-size classes of Pleurobracbia: left to right $=$ small to large; $y$-axis $=$ "probability of survival" for Pleurobracbia (bottom to top $=0$ to 1 ; mean level without significant impact indicated). "Probability of survival" combines here nutritional and predatory impacts in one parameter; $B$ "probability of survival" of Pleurobracbia age classes at indicated abundance of copepods; $C$ "probability of survival " of large Pleurobrachia versus abundance on large copepods. $\mathrm{C}=\mathrm{D}+\mathrm{E} ; D$ hyperbolic assimilation curve indicating the level of maximum uptake of copepods; $E$ detrimental effect of copepods tearing off tentacles of Pleurobracbia (after Greve, 1969, modified)

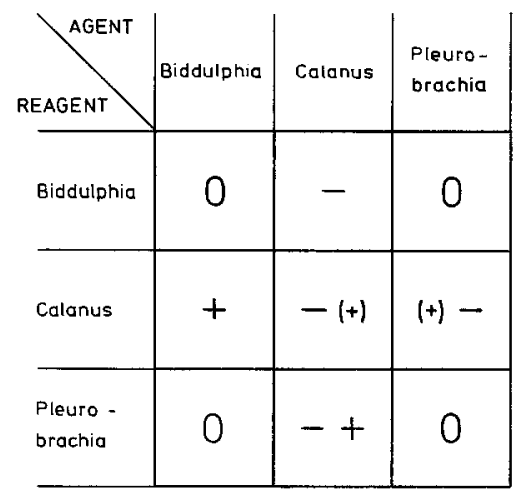

Fig. 3: Example of interaction matrix; impact of each population on $x$-axis (agents) upon each population on $y$-axis (reagents) is indicated by symbols $(+=$ positive impact, $-=$ negative impact, $0=$ no impact, $\pm=$ inverse relationships with age) 
tailed energy budgets and utilisation studies (e.g. Corner et al., 1976). Less attention was paid to the qualitative changes in such trophic relationships during developmental processes within the species involved. This is partly due to the very recent improvements in zooplankton cultivation (see Kinne, 1976, 1977), which make defined developmental stages available for experiments. In addition, today's problem oriented simulation models demand for data upon ecologically significant problems. In

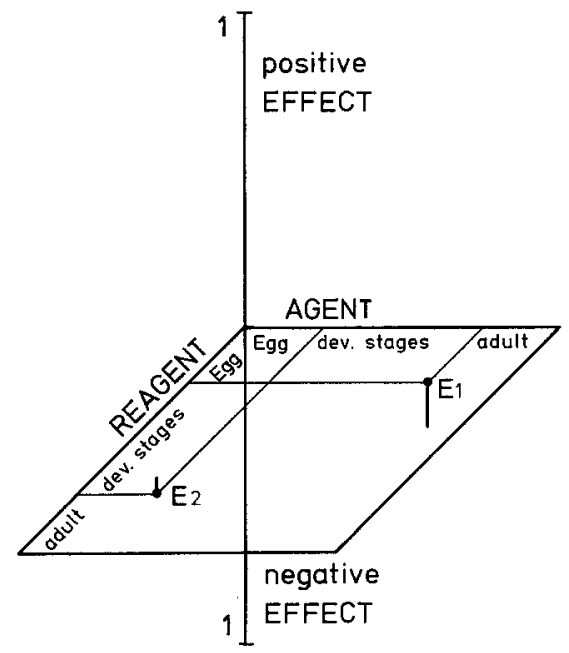

Fig. 4: Agent-reagent-effect-diagramm. Graphic model of population interactions. X-axis $=$ agent's qualities, e.g. age classes; $z$-axis $=$ reagent's qualities, $y$-axis $=$ effect of 1 agent upon 1 reagent (per unit volume and time). Example $1\left(\mathbf{E}_{1}\right): 1$ Agent (adult) feeds upon 2 Reagent (juvenile) and causes. 2 negative effect. Example 2 ( $\left.\mathrm{E}_{2}\right): 2$ Agent (juvenile) is eaten by $1 \mathrm{Re}$ agent (adult) and thereby provides 2 Agent carbon which correlated to the Reagent carbon gives the positive effect (see text)

their valuation crude qualitative data may sometimes be more important than precisely defined functional relationships of physiological system components.

All test organisms originated from North Sea wild plankton caught near Helgoland (North Sea). Pleurobrachia pileus were transferred into the planktonkreisel (Greve, 1968) and other culture equipment (Greve \& Heimberg, in Kinne, 1976) maintaining them over several weeks, and feeding them with wild copepod plankton. Young stages were obtained by concentrating well-fed adult ctenophores in small containers - a procedure stimulating the gonads (Greve, 1969). The juveniles were offered small nauplii selected from wild plankton. A few adults were maintained with the juveniles in order to protect them from maturing copepods.

Calanus belgolandicus also was taken from plankton samples and maintained in culture systems prior to experimentation. They were fed Scripsiella farörense which is utilized by all feeding stages. The adults were maintained in a system resembling the culture apparatus of Sorgeloos et al. (1972). In this apparatus, a sieve collects the eggs and nauplii produced within a $24-\mathrm{h}$ period. The eggs and nauplii were cleaned of faeces and debris and transferred into glass beakers on the taumel- 
tisch (Kinne, 1976) where the containers were gently agitated and regularly cleaned maintaining a favourable concentration of food organisms. Thus all copepods used were derived from laboratory maintenance systems. The experimental temperature $\left(15^{\circ} \mathrm{C}\right)$ was identical to the maintenance temperature. The salinity was $31 \% 0$ which is the mean salinity near Helgoland. The seawater used was filtered flagellate-free. The experimental animals transferred from the maintenance system were feeding (not starved). They were pipette-counted into small jars and then transferred into the experimental container. The water volumes used were 400 or $2000 \mathrm{ml}$, according to the size of the organisms. The experimental containers were kept in dim indirect light without water movement for a $24 \mathrm{~h}$ incubation period. Then the experiment was terminated by formalin fixation. Eggs of both species hatch after approximately $24 \mathrm{~h}$ under these conditions. Therefore the incubation time was shortened in experiments with eggs, and the results interpolated for the whole period.

\section{RESULTS}

Calanus helgolandicus as agent and Pleurobrachia pileus as reagent revealed the following relationship (Fig. 5). A nauplius of $C$. belgolandicus has a minor negative effect upon the newly hatched $P$. pileus. The calculated effect value (of 1 agent upon 1 reagent per 1 1) is 0.02 (see Fig. 4). The effect value increases to 0.3 in adult C. belgolandicus (each value represents at least 3 experiments). The negative effect upon the reagent $P$. pileus drastically changes with size of the ctenophore. The effect

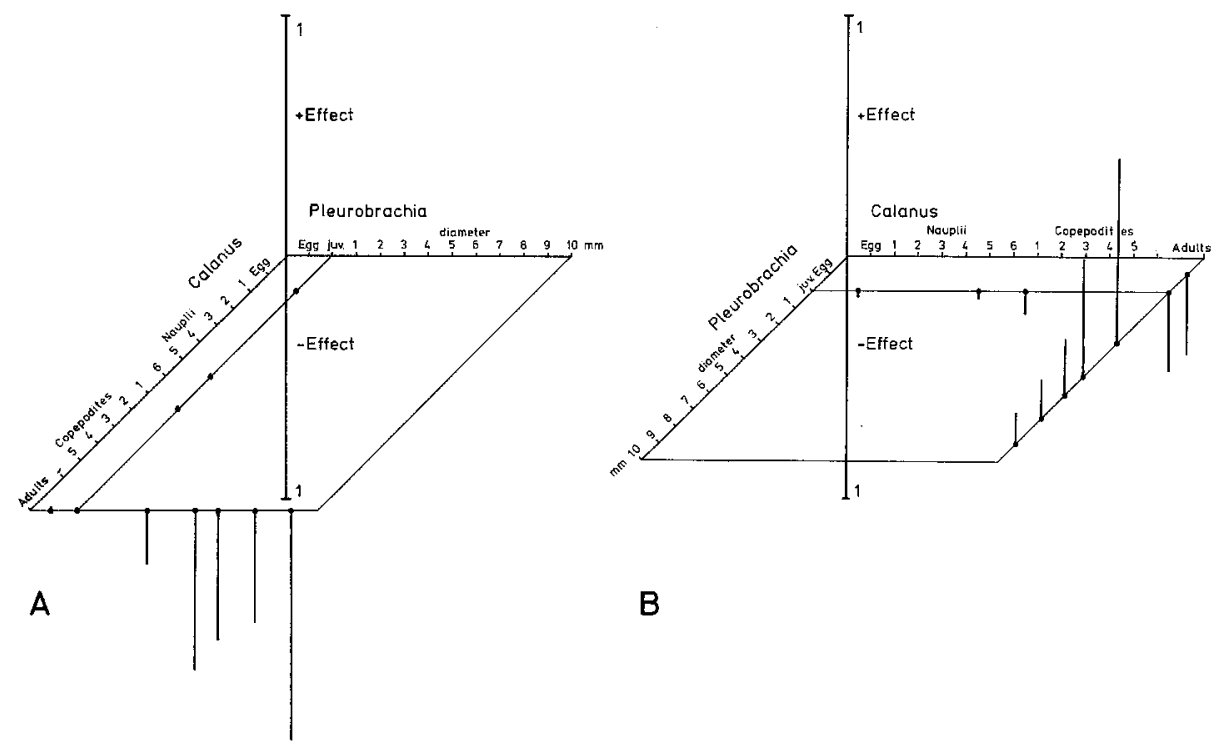

Fig. 5: Agent-reagent-effect-diagram for 10 interspecific interactions of Pleurobrachia pileus and Calanus belgolandicus. A: Agent $P$. pileus reagent $C$. belgolandicus; $\mathrm{B}$ : agent $C$. belgolandicus, reagent $P$. pileus. Each point represents the mean value of three experiments 


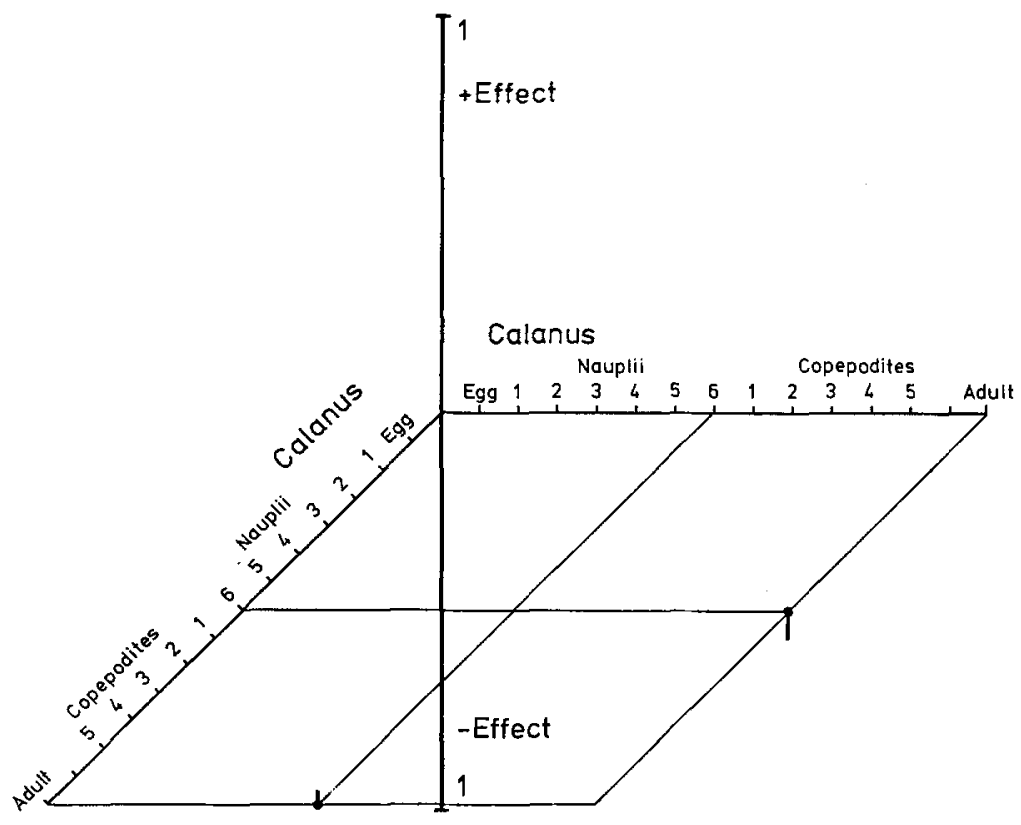

Fig. 6: Agent-reagent-effect-diagram used for graphic display of intraspecific interaction in Calanus. One value (three experiments) represents two data points

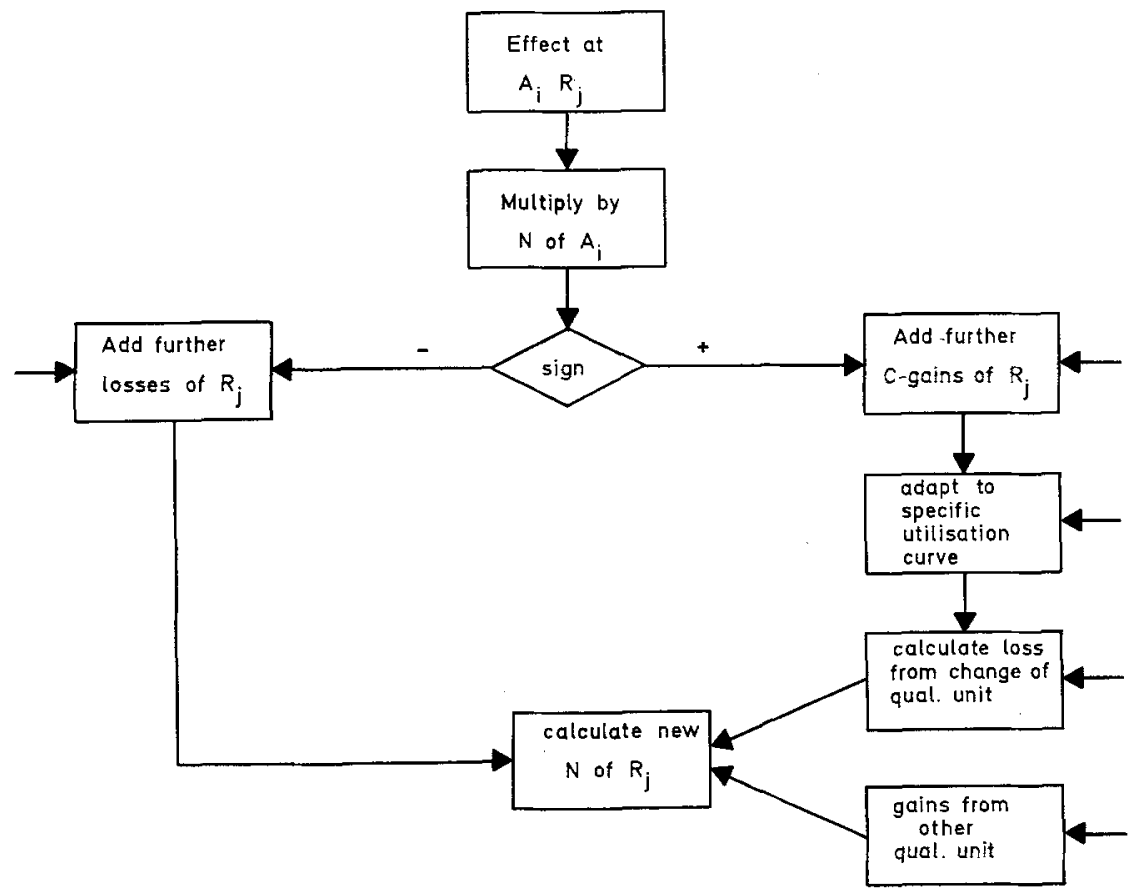

Fig. 7: Sequence of calculation in a simulation model based upon the agent-reagent-effectdiagram. (Aj: Agent of a defined quality; $\mathrm{Rj}$ : reagent of a defined quality; $\mathrm{N}:$ number) 
value for adult $C$. helgolandicus and 4-mm diameter $P$. pileus is +0.8 . It then decreases with growth of the reagent as the carbon ratio changes with the growing ctenophore to +0.1 .

The effect of the agent Pleurobrachia pileus upon the reagent Calanus belgolandicus (Fig. 5) is not a mirror image. The positive effect upon all stages of $C$. belgolandicus does not exceed +0.0002 . The negative effect of large $P$. pileus (maximum -0.9) is much greater then the positive effect of juveniles when compared with the values of agent $C$. belgolandicus and reagent $P$. pileus, respectively. Some problems in the experiments with large $P$. pileus have been due to the small size of the container compared to the catching apparatus of the ctenophore.

In addition to the interspecific interactions of the two populations involved, intraspecific interactions have to be considered before any predictive calculations can start.

Pleurobrachia pileus has not been observed directly interacting with members of its own species. Calanus belgolandicus, on the other hand, is known to be cannibalistic to some extent under laboratory conditions. The intraspecific interaction diagram (Fig. 6) has also been treated as an agent/reagent/effect-diagram. It shows that the values obtained from the experiments can be expressed in the same manner as in interspecific interaction diagrams.

\section{DISCUSSION}

The simple experimental investigations of the inter- and intraspecific interactions of Calanus belgolandicus and Pleurobrachia pileus have produced results which, if completed may be utilized for predictive ecosystem models. This pilot study has neither included all qualities which matter in population (neither health, sex, nor all sizes) nor is it complete with respect to possible interactions. The number of experiments does not even permit proper statistical treatment. Nevertheless, the data obtained open up a possible way of analysing population interactions which are too complex to be easily revealed by field measurements. The possibility of defining interspecific interaction diagrams from short-term experiments permits the construction of simulation models including data obtained in this way, (2) physiological data known from assimilation studies (e.g. Corner et al., 1976), and (3) development data describing the rules of change of quality (in the sense of this model) as a function of nutrition, driving variables and species-specific parameters (Fig. 7).

Population processes predicted from this type of a model are rather limited in their liability; synergic and antagonistic effects of populations, artifacts due to experimental conditions and other possible causes of error are evident. Yet, interpopulative processes, when analysed in situ or in controlled experimental ecosystems (e.g. Mullin et al., 1974; Grice et al., 1977) reveal processes in a multispecies system, but rarely their detailed biological pathways. The method applied here delivers a tool for analysing the critical processes before and after large-scale experiments, or, in situations of quick impact assessment, for a first approximation model.

As to the special case of the populations involved here (Fig. 5, 6) it becomes 
clear that the calanoid copepod, though it serves as food for the adult ctenophore hinders the population of Pleurobrachia pileus from growth. This follows from the effects of adult Calanus helgolandicus upon young ctenophores. By decreasing the number of adult Calanus belgolandicus, the survival of young ctenophores is supported. This demonstrates why subtle decreases in the number of $C$. belgolandicus, due to other factors may well promote a ctenophore bloom with a detrimental effect upon the C. belgolandicus population and possible further implications (Greve \& Parsons, 1977).

Acknowledgements. I wish to thank Mr. F. Reiners for his help with the experiments and with the preparation of data and figures. Drs. C. S. Holling, C. J. Walters and N. C. Sonntag kindly introduced me into simulation modelling; the "Internationales Büro der GKSS" supported this work within the German/Canadian scientific and technological cooperation programme. I am very grateful for all this help.

\section{LITERATURE CITED}

Biologische Anstalt Helgoland. 1976. Jahresbericht 1975, 32.

Corner, E. D. S., Head, R. N. Killvington, C. C. \& Pennicuick, L., 1976. On the nutrition and metabolisms of zooplankton. X. Quantitative aspects of Calanus helgolandicus feeding as a carnivore. J. mar. biol. Ass. U. K. 56, 345-358.

Greve, W., 1968. The "Planktonkreisel", a new device for culturing zooplankton. Mar. Biol. 1, 201-203.

- 1969. Zur Ookologie der Ctenophore Pleurobrachia pileus. Fabr. Math. Nat. Diss. Kiel, $138 \mathrm{pp}$.

- \& Parsons, T. R., 1977. Photosynthesis and fish production: hypothetical effects of climatic change and pollution. Helgoländer wiss. Meeresunters. 30, 83-91.

Grice, G. D., Reeve, M. R. \& Menzel, D. W., 1977. The use of large volume, transparent, enclosed sea-surface water columns in the study of stress of the plankton ecosystems. Helgoländer wiss. Meeresunters. 30,118-133.

Holling, C. S., 1972. Ecological models; a status report. Proc. Int. Symp. Modelling Tech. Wat. Recources Syst. 1, 1-19.

Kinne, O., 1976. Cultivation of marine organisms: water-quality, management and technology. In: Marine ecology. Ed. by O. Kinne. Wiley-Interscience, London. 3 (1), 19-300.

- 1977. Cultivation of animals: research cultivation. In: Marine ecology. Ed. by O. Kinne. Wiley-Interscience, London. 3 (2) (In press).

Landry, M. R., 1976. The structure of marine ecosystems: an alternative. Mar. Biol. 35, 1-7.

- 1977. A review of important concepts concerning species and trophic structure in marine ecosystems. Helgoländer wiss. Meeresunters. 30, 8-14.

Lebour, M., 1922. The food of plankton organisms I. J. mar. biol. Ass. U.K. 12, 644-677.

- 1923. The food of plankton organisms II. J. mar. biol. Ass. U.K. 13, 70-92.

Lillelund, K. \& Lasker, R., 1971. Laboratory studies of predation by marine copepods on fish larvae. Fish. Bull., U.S. 69, 655-667.

Matthews, J. B. L., 1977. The search for a trophic pattern in Korsfjorden, western Norway. Helgoländer wiss. Meeresunters. 30, 47-61.

Mullin, M. M. \& Evans, P. M., 1974. The use of a deep tank in plankton ecology 2. Efficiency of a planktonic food chain. Limnol. Oceanogr. 19, 902-911.

Sorgeloos, P. \& Persoone, G., 1972. Three simple culture devices for aquatic invertebrates and fish larvae with continuous recirculation of the medium. Mar. Biol. 15, 251-254.

Steele, J. H., 1974. The structure of marine ecosystems. Blackwell, Oxford, 128 pp.

- 1976. The role of predation in ecosystem models. Mar. Biol. 35, 9-11. 
Theilacker, G. H. \& Lasker, R., 1974. Laboratory studies of predation by euphausid shrimps on fish larvae. In: The early life history of fish. Springer, Heidelberg, 287-299.

Walters, C. J., Hilborn, R., Oguss, E., Petermann, R. M. \& Stander, J. M., 1974. Development of a simulation model of mallard duck populations. Can. Wildl. Serv. Occ. Pap. 20, 1-35.

Author's address: W. Greve

Biologische Anstalt Helgoland (Meeresstation)

D-2192 Helgoland

Federal Republic of Germany 